\title{
Numerical Modeling of the Additive Manufacturing (AM) Processes of Titanium Alloy
}

\author{
Zhiqiang Fan and Frank Liou \\ Missouri University of Science and Technology \\ USA
}

\section{Introduction}

It is easy to understand why industry and, especially, aerospace engineers love titanium. Titanium parts weigh roughly half as much as steel parts, but its strength is far greater than the strength of many alloy steels giving it an extremely high strength-to-weight ratio. Most titanium alloys are poor thermal conductors, thus heat generated during cutting does not dissipate through the part and machine structure, but concentrates in the cutting area. The high temperature generated during the cutting process also causes a work hardening phenomenon that affects the surface integrity of titanium, and could lead to geometric inaccuracies in the part and severe reduction in its fatigue strength [Benes, 2007]. On the contrary, additive manufacturing (AM) is an effective way to process titanium alloys as AM is principally thermal based, the effectiveness of AM processes depends on the material's thermal properties and its absorption of laser energy rather than on its mechanical properties. Therefore, brittle and hard materials can be processed easily if their thermal properties (e.g., conductivity, heat of fusion, etc.) are favorable, such as titanium. Cost effectiveness is also an important consideration for using additive manufacturing for titanium processing. Parts or products cast and/or machined from titanium and its alloys are very expensive, due to the processing difficulties and complexities during machining and casting. AM processes however, have been found to be very cost effective because they can produce near-net shape parts from these high performance metals with little or no machining [Liou \& Kinsella, 2009]. In the aerospace industry, titanium and its alloys are used for many large structural components. When traditional machining/cast routines are adopted, conversion costs for these heavy section components can be prohibitive due to long lead time and low-yield material utilization [Eylon \& Froes, 1984]. AM processes have the potential to shorten lead time and increase material utilization in these applications. The following sections 1.1, 1.2 and 1.3 summarize the fundamental knowledge for the modeling of additive manufacturing processes.

\subsection{Additive manufacturing}

Additive manufacturing can be achieved by powder-based spray (e.g., thermal spray or cold spray), sintering (e.g., selective laser sintering), or fusion-based processes (or direct metal deposition) which use a laser beam, an electron beam, a plasma beam, or an electric arc as an 
energy source and either metallic powder or wire as feedstock [Kobryn et al., 2006]. For the aerospace industry which is the biggest titanium market in the U.S. [Yu \& Imam, 2007], fusion-based AM processes are more advantageous since they can produce $100 \%$ dense functional metal parts. This chapter will focus on fusion-based AM processes with application to titanium.

Numerical modeling and simulation is a very useful tool for assessing the impact of process parameters and predicting optimized conditions in AM processes. AM processes involve many process parameters, including total power and power intensity distribution of the energy source, travel speed, translation path, material feed rate and shielding gas pressure. These process parameters not only vary from part to part, but also frequently vary locally within a single part to attain the desired deposit shape [Kobryn et al., 2006]. Physical phenomena associated with AM processes are complex, including melting/solidification and vaporization phase changes, surface tension-dominated free-surface flow, heat and mass transfer, and moving heat source. The variable process parameters together with the interacting physical phenomena involved in AM complicate the development of processproperty relationships and appropriate process control. Thus, an effective numerical modeling of the processing is very useful for assessing the impact of process parameters and predicting optimized conditions.

Currently process-scale modeling mainly addresses transport phenomena such as heat transfer and fluid dynamics, which are closely related to the mechanical properties of the final structure. For example, the buoyancy-driven flow due to temperature and species gradients in the melt pool strongly influences the microstructure and thus the mechanical properties of the final products. The surface tension-driven free-surface flow determines the shape and smoothness of the clad. In this chapter, numerical modeling of transport phenomena in fusion-based AM processes will be presented, using the laser metal deposition process as an example. Coaxial laser deposition systems with blown powder as shown in Fig. 1 are considered for simulations and experiments. The material studied is Ti$6 \mathrm{Al}-4 \mathrm{~V}$ for both the substrate and powder. As the main challenges in modeling of fusionbased AM processes are related to melting/solidification phase change and free-surface flow in the melt pool, modeling approaches for these physical phenomena will be introduced in Sections 1.2 and 1.3.

\subsection{Modeling of melting/solidification phase change}

Fusion-based AM processes involve a melting/solidification phase change. Numerical modeling of the solidification of metal alloys is very challenging because a general solidification of metal alloys involves a so-called "mushy region" over which both solid and liquid coexist and the transport phenomena occur across a wide range of time and length scales [Voller, 2006]. A rapidly developing approach that tries to resolve the smallest scales of the solid-liquid interface can be thought of as direct microstructure simulation. In order to simulate the microstructure development directly, the evolution of the interface between different phases or different microstructure constituents has to be calculated, coupled with the physical fields such as temperature and concentration [Pavlyk \& Dilthey, 2004]. To this approach belong phase-field [Beckermann et al., 1999; Boettinger et al., 2002; Caginalp, 1989; Karma \& Rappel, 1996,1998; Kobayashi,1993; Provatas et al., 1998; Steinbach et al., 1996; Warren \& Boettinger, 1995; Wheeler et al., 1992], cellular-automaton [Boettinger et al., 2000; 
Fan et al., 2007a; Gandin \& Rappaz, 1994; Grujicic et al. 2001; Rappaz \& Gandin, 1993; Zhu et al., 2004], front tracking [Juric \& Tryggvason, 1996; Sullivan et al., 1987; Tryggvason et al., 2001], immersed boundary [Udaykumar et al., 1999, 2003] and level set [Gibou et al., 2003; Kim et al. 2000] methods. Due to the limits of current computing power, the above methods only apply to small domains on a continuum scale from about $0.1 \mu \mathrm{m}$ to $10 \mathrm{~mm}$.

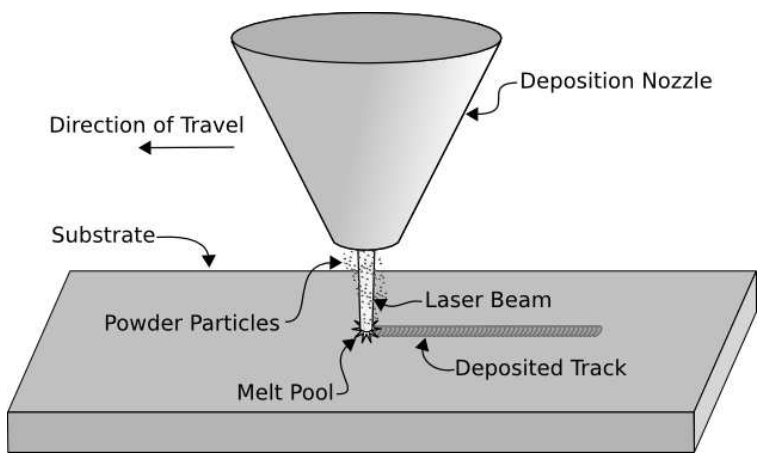

Fig. 1. Schematics of a coaxial laser metal deposition system with powder injection

To treat the effects of transport phenomena at the process-scale $(\sim 1 \mathrm{~m})$, a macroscopic model needs to be adopted, where a representative elementary volume (REV) is selected to include a representative and uniform sampling of the mushy region such that local scale solidification processes can be described by variables averaged over the REV [Voller et al., 2004]. Based on the REV concept, governing equations for the mass, momentum, energy and species conservation at the process scale are developed and solved. Two main approaches have been used for the derivation and solution of the macroscopic conservation equations. One approach is the two-phase model [Beckermann \& Viskanta, 1988; Ganesan \& Poirier, 1990; Ni \& Beckermann, 1991], in which the two phases are treated as separate and separate volume-averaged conservation equations are derived for solid and liquid phases using a volume averaging technique. This approach gives the complete mathematical models for solidification developed today, which have the potential to build a strong linkage between physical phenomena occurring on macroscopic and microscopic scales [Ni \& Incropera, 1995]. However, the numerical procedures of this model are fairly involved since two separate sets of conservation equations need to be solved and the interface between the two phases must be determined for each time step [Jaluria, 2006]. This places a great demand on computational capabilities. In addition, the lack of information about the microscopic configuration at the solid-liquid interface is still a serious obstacle in the implementation of this model for practical applications [Stefanescu, 2002]. An alternative approach to the development of macroscopic conservation equations is the continuum model [Bennon \& Incropera, 1987; Hills et al., 1983; Prantil \& Dawson, 1983; Prescott et al., 1991; Voller \& Prakash, 1987; Voller et al., 1989]. This model uses the classical mixture theory [Muller, 1968] to develop a single set of mass, momentum, energy and species conservation equations, which concurrently apply to the solid, liquid and mushy regions. The numerical procedures for this model are much simpler since the same equations are employed over the entire computational domain, thereby facilitating use of standard, single-phase CFD procedures. In this study, the continuum model is adopted to develop the governing equations. 


\subsection{Modeling of free-surface flow}

In fusion-based AM processes, the melt pool created by the energy source on the substrate is usually modelled as a free-surface flow, in which the pressure of the lighter fluid is not dependent on space, and viscous stresses in the lighter fluid is negligible. The techniques to find the shape of the free surface can be classified into two major groups: Lagrangian (or moving grid) methods and Eulerian (or fixed grid) methods. In Lagrangian methods [Hansbo, 2000; Idelsohn et al., 2001; Ramaswany\& Kahawara, 1987; Takizawa et al., 1992], every point of the liquid domain is moved with the liquid velocity. A continuous remeshing of the domain or part of it is required at each time step so as to follow the interface movement. A special procedure is needed to enforce volume conservation in the moving cells. All of this can lead to complex algorithms. They are mainly used if the deformation of the interface is small, for example, in fluid-structure interactions or small amplitude waves [Caboussat, 2005]. In Eulerian methods, the interface is moving within a fixed grid, and no re-meshing is needed. The interface is determined from a field variable, for example, a volume fraction [DeBar, 1974; Hirt \& Nichols, 1981; Noh \& Woodward, 1976], a level-set [ Sethian, 1996, 1999] or a phase-field [Boettinger et al., 2002; Jacqmin, 1999]. While Lagrangian techniques are superior for small deformations of the interfaces, Eulerian techniques are usually preferred for highly distorted, complex interfaces, which is the case for fusion-based additive manufacturing processes. For example, in AM processes with metallic powder as feedstock, powder injection causes intermittent mergers and breakups at the interface of the melt pool, which needs a robust Eulerian technique to handle.

Among the Eulerian methods, VOF (for Volume-Of-Fluid) [Hirt \& Nichols, 1981] is probably the most widely used. It has been adopted by many in-house codes and built into commercial codes (SOLA-VOF [Nichols et al, 1980], NASA-VOF2D [Torrey et al 1985], NASA-VOF3D [Torrey et al 1987], RIPPLE [Kothe \& Mjolsness 1991], and FLOW3D [Hirt \& Nichols 1988], ANSYS Fluent, to name a few). In this method a scalar indicator function, F, is defined on the grid to indicate the liquid-volume fraction in each computational cell. Volume fraction values between zero and unity indicate the presence of the interface. The VOF method consists of an interface reconstruction algorithm and a volume fraction advection scheme. The features of these two steps are used to distinguish different VOF versions. For modeling of AM processes, an advantage of VOF is that it can be readily integrated with the techniques for simulation of the melting / solidification phase change. VOF methods have gone through a continuous process of development and improvement. Reviews of the historical development of VOF can be found in [Benson, 2002; Rider \& Kothe, 1998; Rudman, 1997; Tang et al., 2004]. In earlier versions of VOF [Chorin, 1980; Debar, 1974; Hirt \& Nichols, 1981; Noh \& Woodward, 1976], reconstruction algorithms are based on a piecewise-constant or "stair-stepped" representation of the interface and advection schemes are at best first-order accurate. These first-order VOF methods are numerically unstable in the absence of surface tension, leading to the deterioration of the interface in the form of flotsam and jetsam [Scardovelli \& Zaleski, 1999]. The current generation of VOF methods approximate the interface as a plane within a computational cell, and are commonly referred to as piecewise linear interface construction (PLIC) methods [Gueyffier et al., 1999; Rider \& Kothe, 1998; Youngs, 1982, 1984]. PLIC-VOF is more accurate and avoids the numerical instability [Scardovelli \& Zaleski, 1999]. 


\section{Mathematical model}

\subsection{Governing equations}

In this study the calculation domain for a laser deposition system includes the substrate, melt pool, remelted zone, deposited layer and part of the gas region, as shown in Fig.2. The continuum model [Bennon \& Incropera, 1987; Prescott et al., 1991] is adopted to derive the governing equations for melting and solidification with the mushy zone. Some important terms for the melt pool have been added in the momentum equations, including the buoyancy force term and surface tension force term, while some minor terms in the original derivation in [Prescott et al., 1991] have been neglected. The molten metal is assumed to be Newtonian fluid, and the melt pool is assumed to be an incompressible, laminar flow. The laminar flow assumption can be relaxed if turbulence is considered by an appropriate turbulence model, such as a low-Reynolds-number $k-\varepsilon$ model [Jones \& Launder, 1973]. The solid and liquid phases in the mushy zone are assumed to be in local thermal equilibrium.

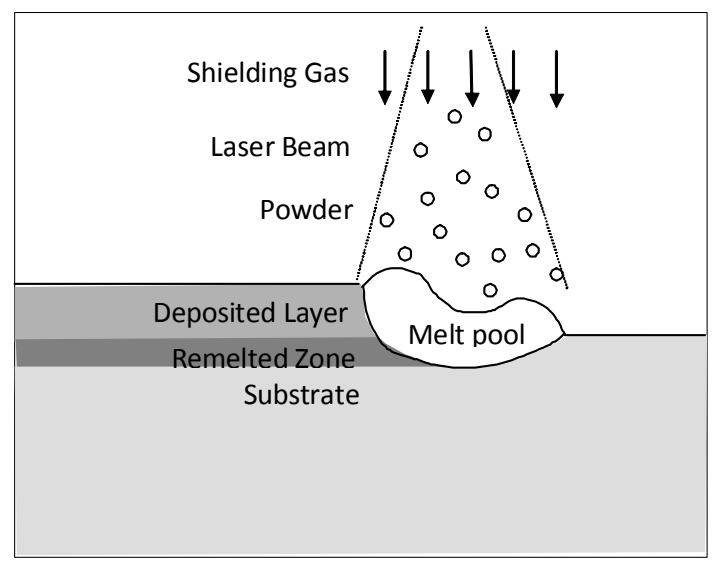

Fig. 2. Schematic diagram of the calculation domain for laser metal deposition process

For the system of interest, the conservation equations are summarized as follows:

Mass conservation:

$$
\frac{\partial \rho}{\partial t}+\nabla \cdot(\rho \mathbf{V})=0
$$

Momentum conservation:

$$
\begin{aligned}
& \frac{\partial}{\partial t}(\rho u)+\nabla \cdot(\rho \mathbf{V} u)=\nabla \cdot\left(\mu_{l} \frac{\rho}{\rho_{l}} \nabla u\right)-\frac{\partial p}{\partial x}-\frac{\mu_{l}}{K_{x}} \frac{\rho}{\rho_{l}}\left(u-u_{s}\right)+\rho \mathbf{g}_{x}\left[1-\alpha\left(T-T_{0}\right)\right]+\mathbf{F}_{S x} \\
& \frac{\partial}{\partial t}(\rho v)+\nabla \cdot(\rho \mathbf{V} v)=\nabla \cdot\left(\mu_{l} \frac{\rho}{\rho_{l}} \nabla v\right)-\frac{\partial p}{\partial y}-\frac{\mu_{l}}{K_{y}} \frac{\rho}{\rho_{l}}\left(v-v_{s}\right)+\rho \mathbf{g}_{y}\left[1-\alpha\left(T-T_{0}\right)\right]+\mathbf{F}_{S y}
\end{aligned}
$$

Energy conservation: 


$$
\frac{\partial}{\partial t}(\rho h)+\nabla \cdot(\rho \mathbf{V h})=\nabla \cdot(k \nabla T)-\nabla \cdot\left[\rho\left(h_{l}-h\right)\left(\mathbf{V}-\mathbf{V}_{s}\right)\right]+S
$$

In equations (1)-(4), the subscripts $s$ and $l$ stand for solid and liquid phase, respectively. $t, \mu$, and $T$ are time, dynamics viscosity and temperature, respectively. $u$ and $v$ are $x$-direction and $y$-direction velocity components. The continuum density $\rho$, vector velocity $V$, enthalpy $h$, and thermal conductivity $k$ are defined as follows:

$$
\begin{gathered}
\rho=g_{s} \rho_{s}+g_{l} \rho_{l} \\
\mathbf{V}=f_{s} \mathbf{V}_{s}+f_{l} \mathbf{V}_{l} \\
h=f_{s} h_{s}+f_{l} h_{l} \\
k=g_{s} k_{s}+g_{l} k_{l}
\end{gathered}
$$

Here the subscripts $s$ and $l$ stand for solid and liquid phase, respectively. $f_{s}$ and $f_{l}$ refer to mass fractions of solid and liquid phases, and $g_{s}$ and $g_{l}$ are volume fractions of solid and liquid phases. To calculate these four quantities, a general practice is that $g_{l}$ (or $g_{s}$ ) is calculated first and then the other three quantities are obtained according to the following relationships:

$$
f_{l}=\frac{g_{l} \rho_{l}}{\rho} \quad f_{s}=\frac{g_{s} \rho_{s}}{\rho} \quad g_{s}+g_{l}=1 \quad f_{s}+f_{l}=1
$$

The volume fraction of liquid $g_{l}$ can be found using different models, such as the level rule, the Scheil model [Scheil, 1942], or the Clyne and Kurz model [Clyne \& Kurz, 1981]. For the target material Ti-6Al-4V, it is assumed that $g_{l}$ is only dependent on temperature. The $g_{l}(\mathrm{~T})$ function is given by [Swaminathan \& Voller, 1992]:

$$
g_{l}=\left\{\begin{array}{cl}
0 & \text { if } T<T_{s} \\
\frac{T-T_{s}}{T_{l}-T_{s}} & \text { if } T_{s} \leq T \leq T_{l} \\
1 & \text { if } T>T_{l}
\end{array}\right.
$$

The phase enthalpy for the solid and the liquid can be expressed as:

$$
\begin{gathered}
h_{s}=\int_{0}^{T} c_{s}(T) d T \\
h_{l}=\int_{0}^{T_{s}} c_{s}(T) d T+\int_{T_{s}}^{T} c_{l}(T) d T+L_{m}
\end{gathered}
$$

where $L_{\mathrm{m}}$ is the latent heat of melting. $c_{s}$ and $c_{l}$ are specific heat of solid and liquid phases.

In Eqs. (2) and (3), the third terms on the right-hand side are the drag interaction terms, and $K_{x}$ and $K_{y}$ are the permeability of the two-phase mushy zone in $\mathrm{x}$ - and $\mathrm{y}$ - directions, which can be calculated from various models [Bhat et al., 1995; Carman, 1937; Drummond \& Tahir, 
1984; Ganesan et al., 1992; Poirier, 1987; West, 1985]. Here the mushy zone is considered as rigid (i.e. a porous media). If the mushy zone is modeled as a slurry region, these two terms can be treated as in [Ni \& Incropera, 1995]. In Eqs. (2) and (3), the fourth terms on the righthand side are the buoyancy force components due to temperature gradients. Here Boussinesq approximation is applied. $\alpha$ is the thermal expansion coefficient. The fifth terms on the right-hand side of Eqs. (2) and (3) are surface tension force components, which will be described in Section 2.2 below. The term $S$ in Eq. (4) is the heat source.

\subsection{Surface tension}

The surface tension force, $F_{S}$, is given by:

$$
\mathbf{F}_{S}=\gamma \kappa \hat{\mathbf{n}}+\nabla_{S} \gamma
$$

where $\gamma$ is surface tension coefficient, $\mathrm{k}$ the curvature of the interface, $\hat{\mathbf{n}}$ the unit normal to the local surface, and $\nabla_{S}$ the surface gradient operator. The term $\gamma \kappa \hat{\mathbf{n}}$ is the normal component of the surface tension force. The term $\nabla_{S} \gamma$ represents the Marangoni effect caused by spatial variations in the surface tension coefficient along the interface due to temperature and/or species gradients. It causes the fluid flow from regions of lower to higher surface tension coefficient.

The conventional approach when dealing with surface tension is to use finite difference schemes to apply a pressure jump at a free-surface discontinuity. More recently, a general practice is to model surface tension as a volume force using a continuum model, either the Continuum Surface Force (CSF) model [Brackbill et al., 1992] or the Continuum Surface Stress (CSS) model [Lafaurie et al., 1994]. The volume force acts everywhere within a finite transition region between the two phases. In this study, the CSF model is adopted, which has been shown to make more accurate use of the free-surface VOF data [Brackbill et al., 1992].

A well-known problem with VOF (and other Eularian methods) modeling of surface tension is so-called "parasitic currents" or "spurious currents", which is a flow induced solely by the discretization and by a lack of convergence with mesh refinement. Under some circumstances, this artificial flow can be strong enough to dominate the solution, and the resulting strong vortices at the interface may lead to catastrophic instability of the interface and may even break-up [Fuster et al., 2009; Gerlach et al. 2006]. Two measures can be taken to relieve or even resolve this problem. One measure is to use a force-balance flow algorithm in which the CSF model is applied in a way that is consistent with the calculation of the pressure gradient field. Thus, imbalance between discrete surface tension and pressuregradient terms can be avoided. Within a VOF framework, such force-balance flow algorithms can be found in [Francois et al., 2006; Y.Renardy \& M. Renardy, 2002; Shirani et al., 2005]. In this study, the algorithm in [Shirani et al., 2005] is followed. The other measure is to get an accurate calculation of surface tension by accurately calculating interface normals and curvatures from volume fractions. For this purpose, many methods have been developed, such as those in [Cummins et al, 2005; Francois et al., 2006; López \& Hernández, 2010; Meier et al., 2002; Pilliod Jr. \& Puckett, 2004; Y.Renardy \& M. Renardy, 2002]. The method we use here is the height function (HF) technique, which has been shown to be second-order accurate, and superior to those based on kernel derivatives of volume fractions 
or RDF distributions [Cummins et al, 2005; Francois et al., 2006; Liovic et al., 2010]. Specifically, we adopt the HF technique in [López \& Hernández, 2010] that has many improvements over earlier versions (such as that in [Torrey et al., 1985]) of HF, including using an error correction procedure to minimize estimation error. Within the HF framework, suppose the absolute value of the y-direction component of the interface normal vector is larger than the $\mathrm{x}$-direction component, interface curvature (in 2D) is given by

$$
\kappa=\frac{H_{x x}}{\left(1+H_{x}{ }^{2}\right)^{3 / 2}}
$$

where $H$ is the height function, $H_{x}$ and $H_{x x}$ are first-order and second-order derivatives of $H$, respectively. $H_{x}$ and $H_{x x}$ are obtained by using a finite difference formula. Interface normals are calculated based on the Least-Squares Fit method from [Aulisa et al., 2007].

\subsection{Tracking of the free surface}

The free surface of the melt pool is tracked using the PLIC-VOF [Gueyffier et al., 1999; Scardovelli \& Zaleski, 2000, 2003]. The Volume of Fluid function, F, satisfies the following conservation equation:

$$
\frac{\partial F}{\partial t}+(\mathbf{V} \cdot \nabla) F=0
$$

The PLIC-VOF method consists of two steps: interface reconstruction and interface advection. In 2D calculation, a reconstructed planar surface becomes a straight line which satisfies the following equation:

$$
n_{x} x+n_{y} y=d
$$

where $n_{x}$ and $n_{y}$ are $\mathrm{x}$ and $\mathrm{y}$ components of the interface normal vector. $d$ is a parameter related to the distance between the line and the coordinate origin of the reference cell. In the interface reconstruction step, $n_{x}$ and $n_{y}$ of each cell are calculated based on volume fraction data, using the Least-Squares Fit method from [Aulisa et al., 2007]. Then the parameter $d$ is determined to match the given volume fraction. Finally given the velocity field, the reconstructed interface is advected according to the combined Eulerian-Lagrangian scheme in [Aulisa et al., 2007].

\subsection{Boundary conditions}

Energy balance at the free surface satisfies the following equation:

$$
k \frac{\partial T}{\partial \mathbf{n}}=\frac{\eta\left(P_{\text {laser }}-P_{\text {atten }}\right)}{\pi R^{2}}-h_{c}\left(T-T_{\infty}\right)-\varepsilon \sigma\left(T^{4}-T_{\infty}^{4}\right)-\dot{m}_{e} L_{v}
$$

where terms on the right-hand side are laser irradiation, convective heat loss, radiation heat loss and evaporation heat loss, respectively. $P_{\text {laser }}$ is the power of laser beam, $P_{\text {atten }}$ the power attenuated by the powder cloud, $R$ the radius of laser beam spot, $\eta$ the laser absorption coefficient, $\dot{m}_{e}$ the evaporation mass flux, $L_{v}$ the latent heat of evaporation, $h_{c}$ the heat 
convective coefficient, $\varepsilon$ emissivity, $\sigma$ the Stefan-Boltzmann constant, and $\mathbf{n}$ the normal vector at the local interface. $\dot{m}_{e}$ can be evaluated according to the "overall evaporation model" in [Choi et al., 1987], and $\mathrm{P}_{\text {atten }}$ can be calculated according to [Frenk et al., 1997] with a minor modification.

On the bottom surface and side surfaces, boundary conditions are given by

$$
\begin{gathered}
k \frac{\partial T}{\partial \mathbf{n}}+h_{c}\left(T-T_{\infty}\right)=0 \\
\mathbf{V}=0
\end{gathered}
$$

Note that the radiation heat loss at these surfaces is neglected due to the fact that the temperature differences at these surfaces are not large.

\subsection{Numerical Implementation}

Finite difference and finite volume methods are used for spatial discretization of the governing equations. Staggered grids are employed where the temperatures, pressures and VOF function are located at the cell center and the velocities at the walls. In the numerical implementation, material properties play an important role. The material properties are generally dependent on temperature, concentration, and pressure. For fusion-based additive manufacturing processes, the material experiences a large variation from room temperature to above the melting temperature. For Ti-6Al-4V, many material properties experience large variations over this wide temperature range, as shown in Table 1. For example, the value of specific heat varies from $546 \mathrm{~J}^{-} \mathrm{K}^{-1}-\mathrm{kg}^{-1}$ at room temperature to $831 \mathrm{~J}^{-} \mathrm{K}^{-1}-\mathrm{kg}^{-1}$ at liquidus temperature. Thermal conductivity varies from 7 to $33.4 \mathrm{~W}-\mathrm{m}^{-1}-\mathrm{K}^{-1}$ over the same temperature range. Thus, the temperature dependence of the properties dominates, which necessitates a coupling of the momentum equations with the energy equation and gives rise to strong nonlinearity in the conservation equations.

The variable properties have two effects on the numerical solution procedure [Ferziger \& Peric, 2002]. First, although an incompressible flow assumption is made, the thermophysical properties need to be kept inside the differential operators. Thus, solution methods for incompressible flow can be used. Second, the momentum and energy conservation equations have to be solved in a coupled way. In this study, the coupling between momentum and energy equations is achieved by the following iterative scheme:

1. Eqs. (1) - (3) and the related boundary conditions are solved iteratively using a two-step projection method [Chorin, 1968] to obtain velocities and pressures. Thermo-physical properties used in this step are computed from the old temperature field. At each time step, the discretized momentum equations calculate new velocities in terms of an estimated pressure field. Then the pressure field is iteratively adjusted and velocity changes induced by each pressure correction are added to the previous velocities. This iterative process is repeated until the continuity equation is satisfied under an imposed tolerance by the newly computed velocities. This imposes a requirement for solving a linear system of equations. The preconditioned Bi-CGSTAB (for Bi-Conjugate Gradient Stabilized) method [Barrett et al., 1994] is used to solve the linear system of equations. 
2. Eq. (4) is solved by a method [Knoll et al., 1999] based on a finite volume discretization of the enthalpy formulation of Eq. (4). The finite volume approach ensures that the numerical scheme is locally and globally conservative, while the enthalpy formulation can treat phase change in a straightforward and unified manner. Once new temperature field is obtained, the thermo-physical properties are updated.

3. Equation (15) is solved using the PLIC-VOF [Gueyffier et al., 1999; Scardovelli \& Zaleski, 2000, 2003] to obtain the updated free surface and geometry of the melt pool.

4. Advance to the next time step and back to step 1 until the desired process time is reached.

\begin{tabular}{|c|c|c|}
\hline Physical Properties & Value & Reference \\
\hline Liquidus temperature $(K)$ & 1923.0 & [Mills, 2002] \\
\hline Solidus temperature $(K)$ & 1877.0 & [Boyer et al., 1994] \\
\hline Evaporation temperature $(K)$ & 3533.0 & [Boyer et al., 1994] \\
\hline Solid specific heat $\left(\mathrm{kg}^{-1} \mathrm{~K}^{-1}\right)$ & $\begin{cases}483.04+0.215 T & T \leq 1268 K \\
412.7+0.1801 T & 1268<T \leq 1923\end{cases}$ & [Mills, 2002] \\
\hline Liquid specific heat $\left(J \mathrm{~kg}^{-1} \mathrm{~K}^{-1}\right)$ & 831.0 & [Mills, 2002] \\
\hline $\begin{array}{l}\text { Thermal conductivity } \\
\left(\mathrm{W} \mathrm{m} \mathrm{m}^{-1} \mathrm{~K}^{-1}\right)\end{array}$ & $\begin{cases}1.2595+0.0157 T & T \leq 1268 K \\
3.5127+0.0127 T & 1268<T \leq 1923 \\
-12.752+0.024 T & T>1923\end{cases}$ & [Mills, 2002] \\
\hline Solid density $\left(\mathrm{kg} \mathrm{m}^{-3}\right)$ & $4420-0.154(\mathrm{~T}-298 \mathrm{~K})$ & [Mills, 2002] \\
\hline Liquid density $\left(\mathrm{kg} \mathrm{m}^{-3}\right)$ & $3920-0.68(\mathrm{~T}-1923 \mathrm{~K})$ & [Mills, 2002] \\
\hline Latent heat of fusion $\left(\mathrm{J} \mathrm{kg}^{-1}\right)$ & $2.86 \times 10^{5}$ & [Mills, 2002] \\
\hline $\begin{array}{l}\text { Latent heat of evaporation } \\
\left(\mathrm{J} \mathrm{kg}^{-1}\right)\end{array}$ & $9.83 \times 10^{6}$ & [Mills, 2002] \\
\hline Dynamic viscosity $\left(\mathrm{N} \mathrm{m}^{-1} \mathrm{~s}^{-1}\right)$ & $\begin{array}{l}3.25 \times 10^{-3}(1923 \mathrm{~K}) 3.03 \times 10^{-3}(1973 \mathrm{~K}) \\
2.66 \times 10^{-3}(2073 \mathrm{~K}) 2.36 \times 10^{-3}(2173 \mathrm{~K})\end{array}$ & [Mills, 2002] \\
\hline Radiation emissivity & $0.1536+1.8377 \times 10^{-4}(\mathrm{~T}-300.0 \mathrm{~K})$ & [Lips\&Fritsche, 2005] \\
\hline Surface tension $\left(\mathrm{N} \mathrm{m}^{-1}\right)$ & $1.525-0.28 \times 10^{-3}(\mathrm{~T}-1941 \mathrm{~K})^{\mathrm{a}}$ & [Mills, 2002] \\
\hline $\begin{array}{l}\text { Thermal expansion coefficient } \\
\left(\mathrm{K}^{-1}\right)\end{array}$ & $1.1 \times 10^{-5}$ & [Mills, 2002] \\
\hline Laser absorption coefficient & 0.4 & \\
\hline Ambient temperature (K) & 300 & \\
\hline 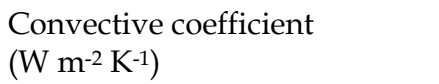 & 10 & \\
\hline
\end{tabular}

Table 1. Material properties for Ti-6Al-4V and main process parameters used in simulations. aValue for commercially pure titanium was used.

The time step is taken at the level of $10^{-6} \mathrm{~s}$ initially and adapted subsequently according to the convergence and stability requirements of the Courant-Friedrichs-Lewy (CFL) condition, the explicit differencing of the Newtonian viscous stress tensor, and the explicit treatment of the surface tension force. 


\section{Simulation results and model validation}

The parameters for the simulation were chosen based on the capability of our experimental facilities to compare the simulation results with the experimental measurements. A diode laser deposition system (the LAMP system of Missouri S\&T) and a YAG laser deposition system at South Dakota School of Mines and Technology (SDSMT) were used for simulations and experiments. Ti-6Al-V4 plates with a thickness of 0.25 inch were selected as substrates. Ti-6Al-V4 powder particles with a diameter from 40 to $140 \mu \mathrm{m}$ were used as deposit material. Fig. 3 shows the typical simulation results for temperature, velocity and VOF function.

The numerical model was validated from different aspects. First, it was validated in terms of melt pool peak temperature and melt pool length. The experiments were performed on the LAMP system as shown in Fig. 4. The system consists of a diode laser, powder delivery unit, 5-axis CNC machine, and monitoring subsystem. The laser system used was a Nuvonyx ISL-1000M Diode Laser that is rated for $1 \mathrm{~kW}$ of output power. The laser emits at $808 \mathrm{~nm}$ and operates in the continuous wave $(\mathrm{CW})$ mode. The laser spot size is $2.5 \mathrm{~mm}$. To protect oxidization of Ti-6Al-V4, the system is covered in an environmental chamber to supply argon gas. The melt pool peak temperature is measured by a non-contact optical pyrometer that is designed for rough conditions, such as high ambient temperatures or electromagnetic interferences. A laser sight within the pyrometer allows for perfect alignment and focal length positioning; the spot size is $2.6 \mathrm{~mm}$ which encompasses the melt pool. The pyrometer senses the maximum temperature between 400 and 2500 (degrees C) and correlates the emissivity of the object to the resulting measurement. Temperature measurements are taken in real-time at 500 or $1000 \mathrm{~Hz}$ using a National Instruments real-time control system. A 4-20 mA signal is sent to the real-time system which is converted to degrees Celsius, displayed to the user and simultaneously recorded to be analyzed at a later date. Due to the collimator, the pyrometer is mounted to the Zaxis of the CNC at 42 (degrees) and is aligned with the center of the nozzle. Temperature measurements recorded the rise and steady state temperatures and the cooling rates of the melt pool. A complementary metal oxide semiconductor (CMOS) camera was installed right above the nozzle head for a better view in dynamically acquiring the melt pool image. The melt pool dimensions can be calculated from the image by the image process software.

Fig. 5 and Fig. 6 show the measured and predicted melt pool peak temperatures at different laser power levels and at different travel speeds, respectively. It can be seen from the plot that the general trend between simulation and experiment is consistent. At different power intensity level, there is a different error from $10 \mathrm{~K}$ (about $0.5 \%$ ) to $121 \mathrm{~K}$ (about 5\%). Fig. 7 shows measured and predicted melt pool length at different laser power levels. The biggest disagreement between measured and simulated values is about $7 \%$. It can be seen that the differences between measured and predicted values at higher power intensities (higher power levels or slower travel speeds) are generally bigger than those at lower power intensities. This can be explained by the two-dimensional nature of the numerical model. A 2D model does not consider the heat transfer in the third direction. At a higher power level, heat transfer in the third dimension is more significant. 


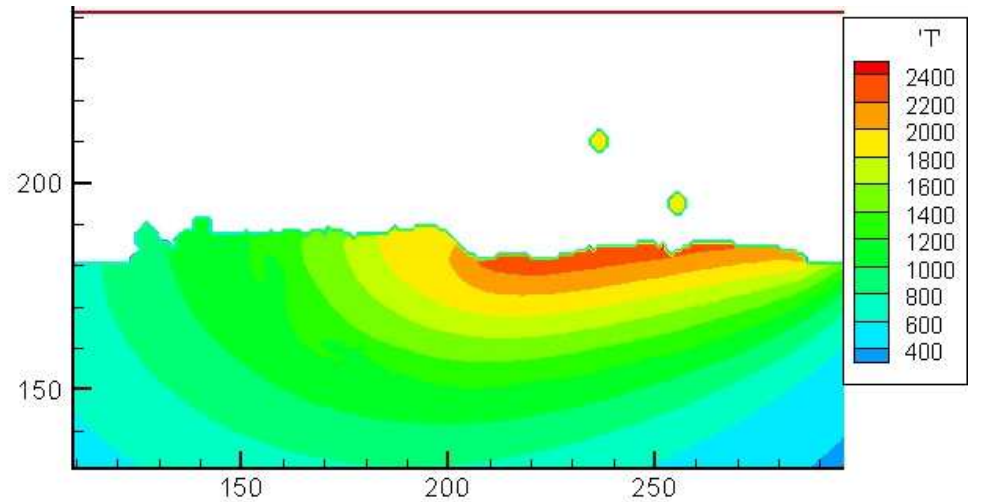

(a) Temperature field of the region around the melt pool

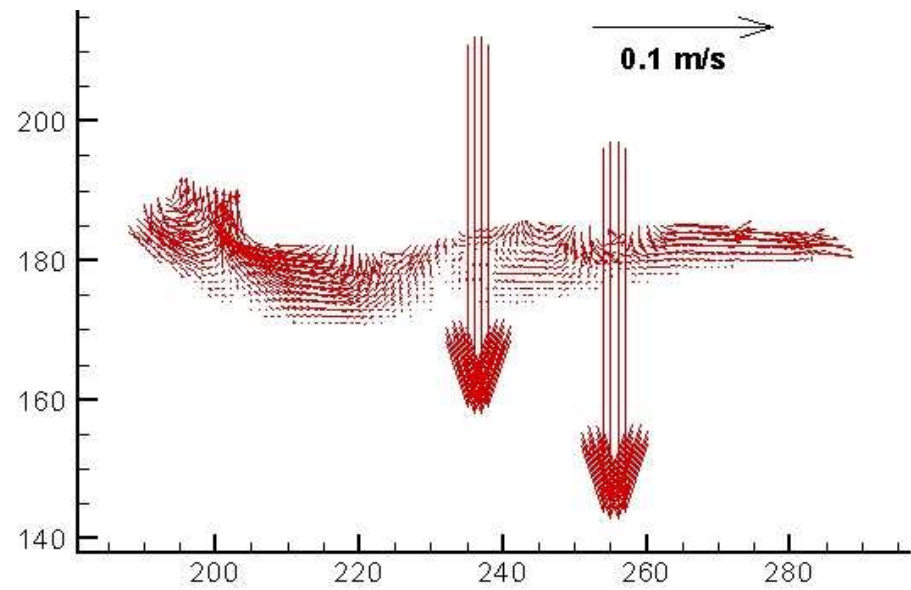

(b) Velocity field of the melt pool and falling powder particles

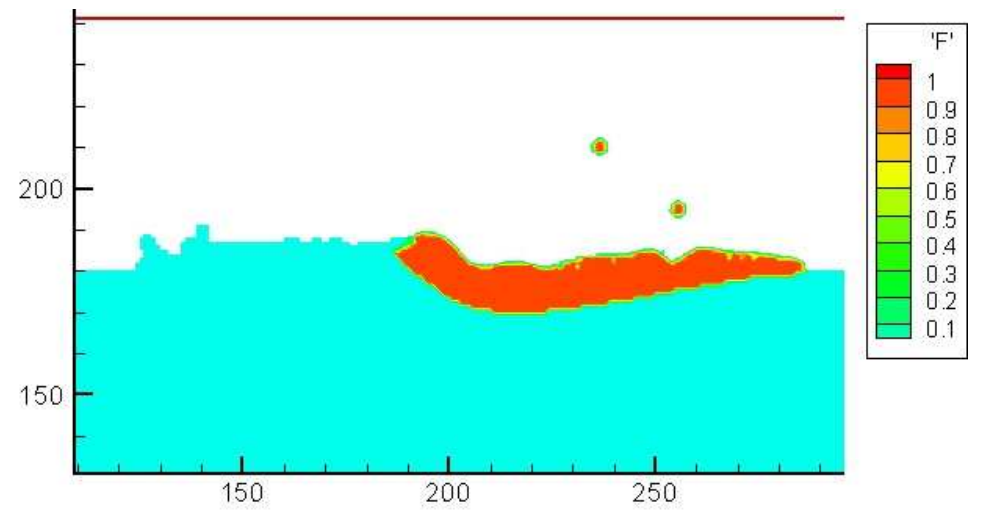

(c) VOF field of part of the region around the melt pool

Fig. 3. Simulation results of laser deposition of Ti-6Al-4V 


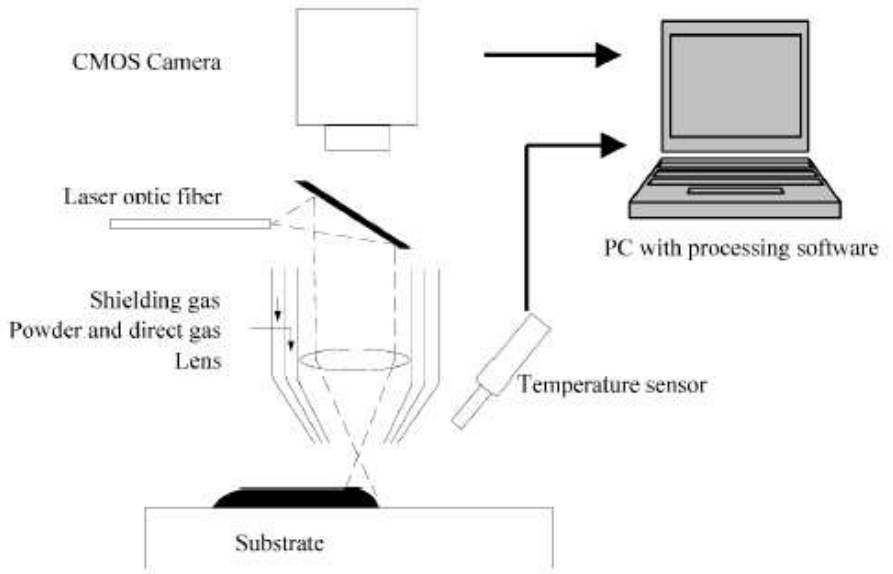

Fig. 4. Schematic of experimental setup

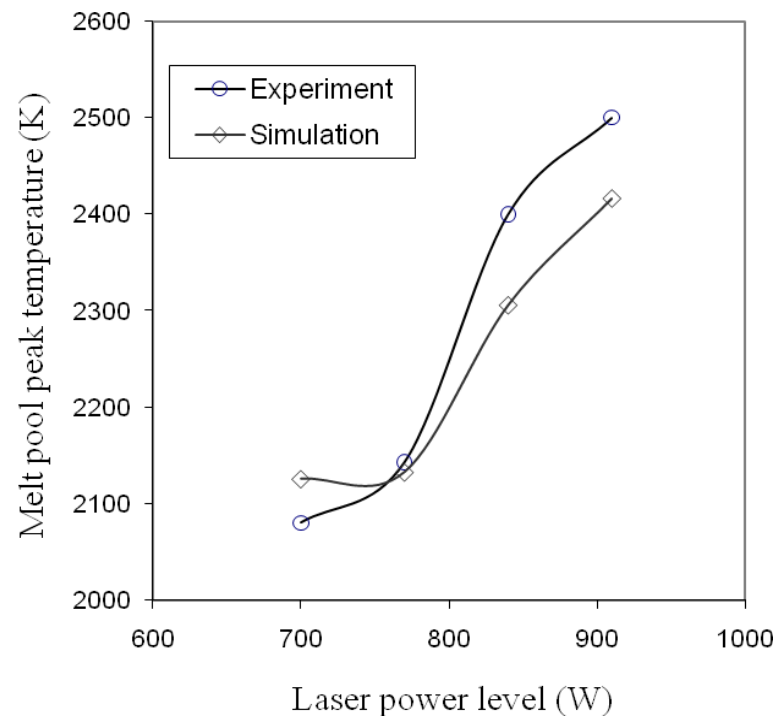

Fig. 5. Melt pool peak temperature comparison between simulation and experiment at different laser power levels (powder mass flow rate $=4.68 \mathrm{~g} / \mathrm{min}$., travel speed $=20$ inch/min.) 


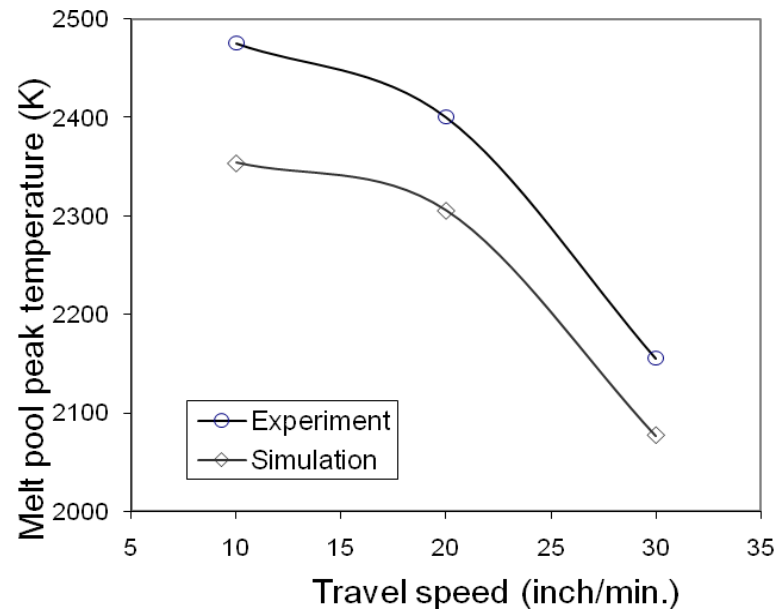

Fig. 6. Melt pool peak temperature comparison between simulation and experiment at different travel speeds (powder mass flow rate $=4.68 \mathrm{~g} / \mathrm{min}$., laser power $=700 \mathrm{~W}$ )

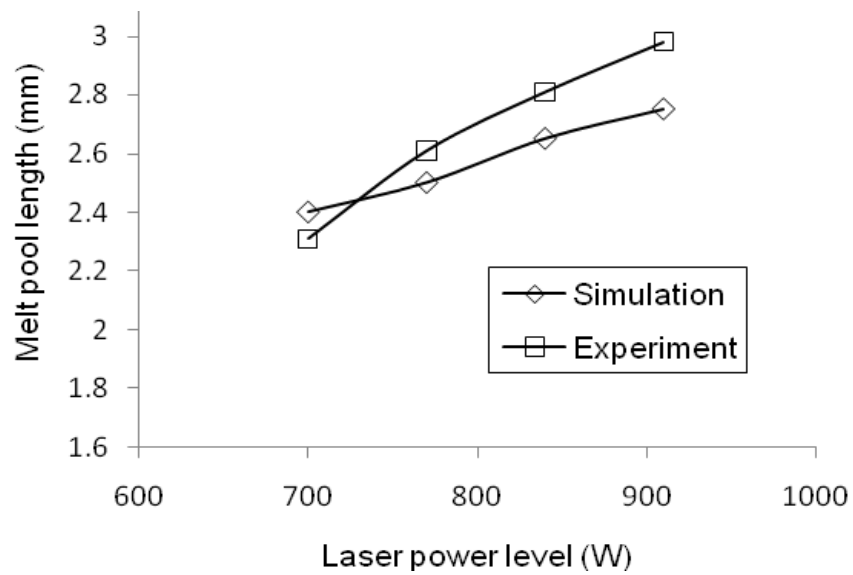

Fig. 7. Melt pool length comparisons between simulation and experiment at different power levels (powder mass flow rate $=4.68 \mathrm{~g} / \mathrm{min}$., travel speed $=20 \mathrm{inch} / \mathrm{min}$.)

The samples were cross-sectioned using a Wire-EDM machine to measure dilution depth. An SEM (Scanning Electron Microscope) line trace was used to determine the dilution of the clad layer. The deposited Ti-6Al-4V is of Widmansttaten structure. The substrate has a rolled equi-axed alpha plus beta structure. Even though these two structures are are easily distinguishable, the HAZ is large and has a martensitic structure that can be associated with it. Hence a small quantity of tool steel in the order of $5 \%$ was mixed with Ti-6Al- $4 \mathrm{~V}$. The small quantity makes sure that it does not drastically change the deposit features of a $100 \%$ Ti-6Al-4V deposit. At the same time, the presence of $\mathrm{Cr}$ in tool steel makes it easily identifiable by means of EDS scans using SEM. Simulation and experimental results of dilution depth are shown in Figs. 8 - 10. 


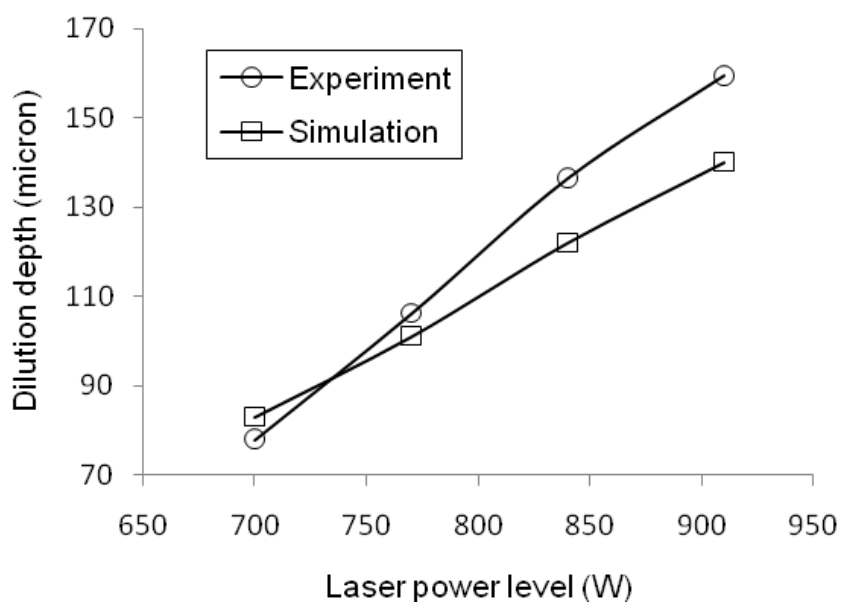

Fig. 8. Comparison of dilution depth between simulation and experiment at different power levels (powder mass flow rate $=4.68 \mathrm{~g} / \mathrm{min}$., travel speed $=20 \mathrm{inch} / \mathrm{min}$.)

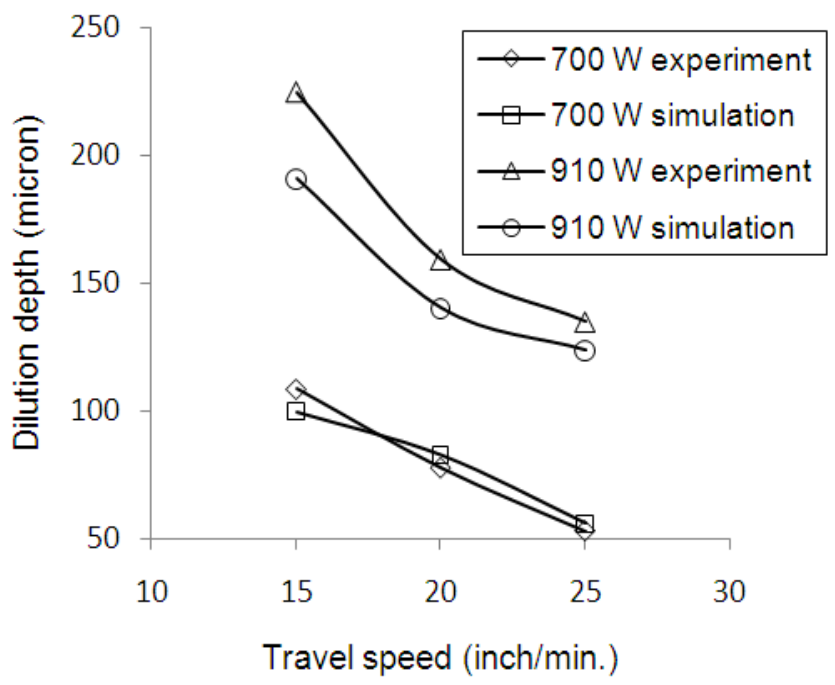

Fig. 9. Comparison of dilution depth between simulation and experiment at different travel speeds and different laser power levels (powder mass flow rate $=4.68 \mathrm{~g} / \mathrm{min}$.) 


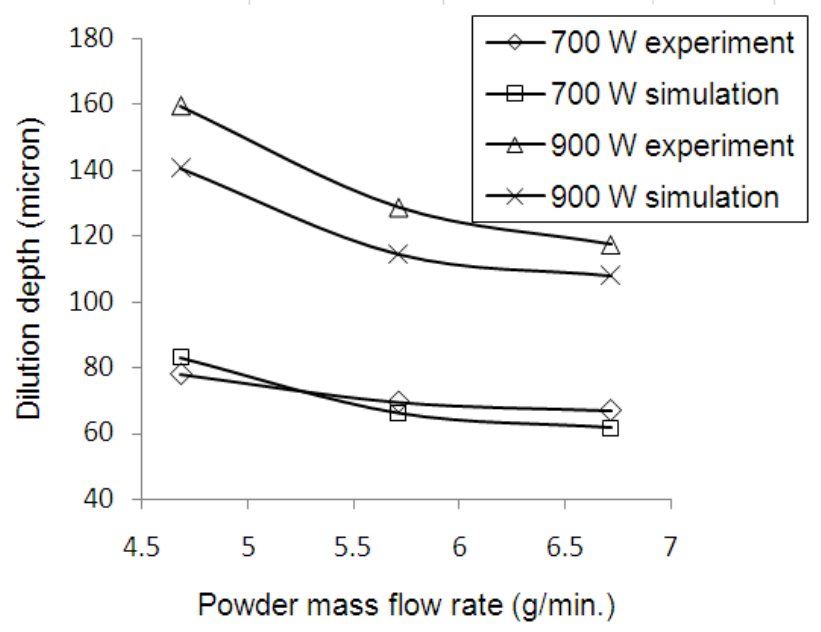

Fig. 10. Comparison of dilution depth between simulation and experiment at different powder mass flow rates and different laser power levels (travel speed $=20 \mathrm{inch} / \mathrm{min}$.)

Good agreements between measured and simulated dilution depths can be found in Figs. 810. The differences are from about $4.8 \%$ to $15.1 \%$. It can be seen that an increase in the laser power will increase the dilution depth. An increase in the laser travel speed will decrease the dilution depth. It is clear that the dilution depth has a linear dependence on the laser power and the laser travel speed. This is easy to understand. As the laser power increases, more power is available for melting the substrate. As travel speed decreases, the laser material interaction time is extended. From Fig. 10, it can be seen that an increase in powder mass flow rate will decrease the dilution depth. But this effect is more significant at a higher level of laser power. It is likely that at a lower level of laser power, a significant portion of laser energy is consumed to melt the powder. Hence the energy available is barely enough to melt the substrate. Detailed discussion can be found in [Fan et al, 2006, 2007b; Fan, 2007].

Finally, the numerical model was validated in terms of its capability for predicting the lackof-fusion defect. The test was performed using the YAG laser deposition system at South Dakota School of Mines and Technology (SDSMT). The simulation model determined that 1,200 watts would be the nominal energy level for the test. This means that based on the model, lack of fusion should occur when the laser power is below $1200 \mathrm{~W}$. In accordance with the test matrix, seven energy levels were tested: nominal, nominal $\pm 10 \%$, nominal \pm $20 \%$, and nominal $\pm 30 \%$. Based on the predicted nominal value of 1,200 watts, the seven energy levels in the test matrix are 840, 960, 1080, 1200, 1320, 1440, and 1540 watts. The deposited Ti-6Al-4V specimens were inspected at Quality Testing Services Co. using ultrasonic and radiographic inspections to determine the extent of lack-of-fusion in the specimens. The determination of whether or not there exists lack of fusion in a deposited specimen can be explained using Figs. 11 - 13. First a substrate without deposit on it was inspected as shown in Fig. 11. Notice that the distance between two peaks are the thickness of the substrate. Then laser deposited specimens were inspected. If there is lack of fusion in a deposited specimen, some form of peaks can be found between the two high peaks in the 
ultrasonic graph, the distance of which is the height of the deposition and the thickness of the substrate. Fig. 12 shows an ultrasonic graph of a deposited specimen with a very good deposition. The ultrasonic result indicates there is not lack of fusion occurring between layers and the interface. The distance between two peaks is the height of the deposition and the thickness of the substrate. For the deposition as shown in Fig. 13, the lack of fusion occurs as the small peak (in circle) appears between two high peaks. The results revealed that no lack-of-fusion was detected in specimens deposited using 1,200 watts and higher energy levels. However, lack-of-fusion was detected in specimens deposited from lower energy levels (minus $10 \%$ up to minus $30 \%$ of 1,200 watts.). The test results validated the simulation model.

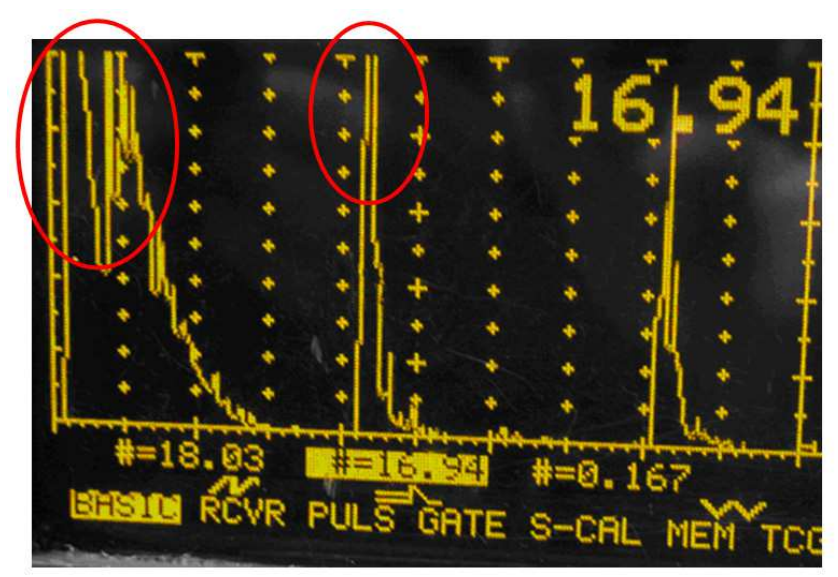

Fig. 11. Ultrasonic graph of a Ti-6Al-4V substrate

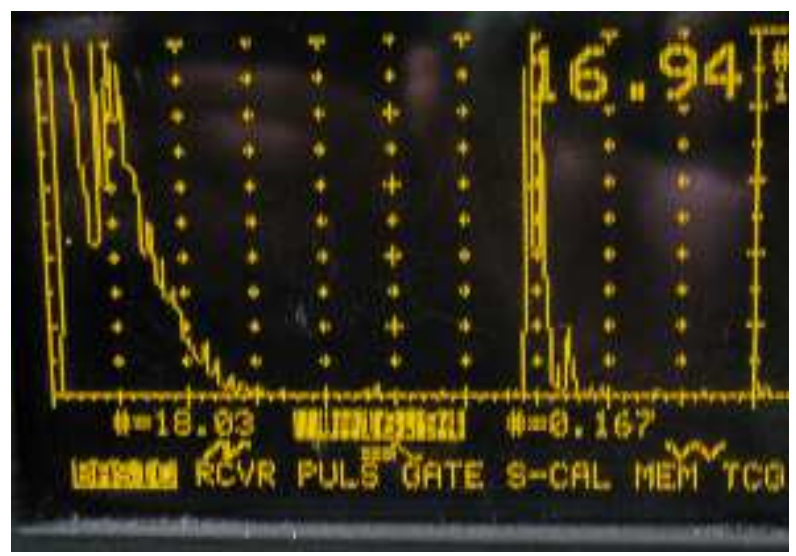

Fig. 12. Ultrasonic graph of a laser deposited Ti-6Al-4V specimen without lack of fusion 


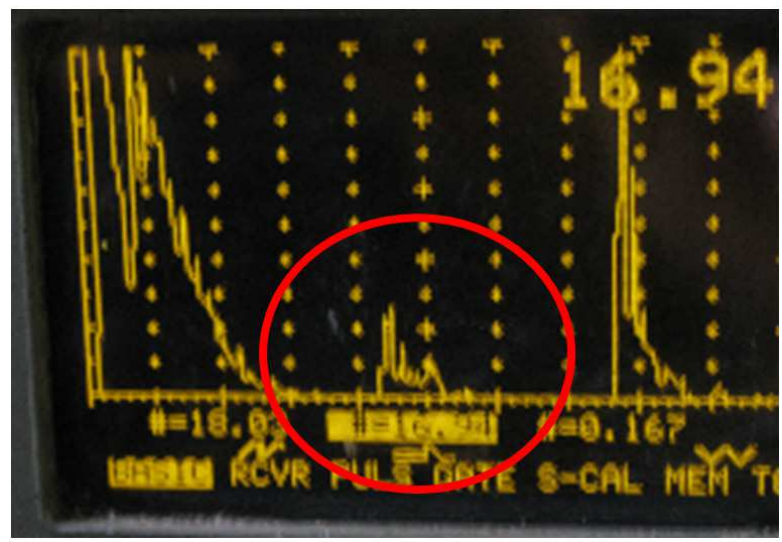

Fig. 13. Ultrasonic graph of a laser deposited Ti-6Al-4V specimen with lack of fusion

\section{Conclusion}

This chapter has outlined the approach for mathematical and numerical modeling of fusionbased additive manufacturing of titanium. The emphasis is put on modeling of transport phenomena associated with the process, including heat transfer and fluid flow dynamics. Of particular interest are the modeling approaches for solidification and free surface flow with surface tension. The advantages and disadvantages of the main modeling approaches are briefly discussed. Based on the comparisons, the continuum model is adopted for modeling of melting/solidification phase change, and the VOF method for modeling of free-surface flow in the melt pool.

The laser deposition process is selected as an example of fusion-based additive manufacturing processes. The governing equations, auxiliary relationships, and boundary conditions for the solidification system and free-surface flow are presented. The main challenge for modeling of the surface tension-dominant free surface flow is discussed and the measures to overcome the challenge are given. The numerical implementation procedures are outlined, with a focus on the effects of variable material property on the discretization schemes and solution algorithms. Finally the simulation results are presented and compared with experimental measurements. A good agreement has been obtained and thus the numerical model is validated. The modeling approach can be applied to other fusion-based manufacturing processes, such as casting and welding.

\section{Acknowledgment}

This research was partially supported by the National Aeronautics and Space Administration Grant Number NNX11AI73A, the grant from the U.S. Air Force Research Laboratory, and Missouri S\&T's Intelligent Systems Center and Manufacturing Engineering program. Their support is greatly appreciated. The help from Dr. Kevin Slattery and Mr. Hsin Nan Chou at Boeing-St Louis and Dr. James Sears at South Dakota School of Mines and Technology are also acknowledged. 


\section{References}

Aulisa, E.; Manservisi, S.; Scardovelli, R. \& Zaleski, S. (2007). Interface reconstruction with least-squares fit and split advection in three-dimensional Cartesian geometry, Journal of Computational Physics, Vol. 225, No.2, (August 2007), pp. 2301-2319, ISSN 0021-9991

Barrett, R.; Berry, M.; Chan, T. F.; Demmel, J.; Donato, J.; Dongarra, J.; Eijkhout, V.; Pozo, R.; Romine, C. \& Van der Vorst, H. (1994). Templates for the Solution of Linear Systems: Building Blocks for Iterative Methods (2nd Edition), SIAM, ISBN 978-0-898713-28-2 Philadelphia, PA

Beckermann C. \& Viskanta, R. (1988). Double-diffusive convection during dendritic solidification of a binary mixture. PCH: Physicochemical Hydrodynamics, Vol. 10, No.2, pp. 195-213, ISSN 0191-9059

Beckermann, C.; Diepers, H.-J.; Steinbach, I.; Karma, A. \& Tong X. (1999). Modeling Melt Convection in Phase-Field Simulations of Solidification, Journal of Computational Physics, Vol. 154, No.2, (September 1999), pp. 468-496, ISSN 0021-9991

Benes, J. (2007). Cool Tips for Cutting Titanium, In: American Mechanist, 26.09.2011, Available from http://www.americanmachinist.com/304/Issue/Article/False/77297/

Bennon, W. D. \& Incropera, F. P. (1987). A continuum model for momentum, heat and species transport in binary solid-liquid phase change systems-I. Model formulation. International Journal of Heat and Mass Transfer, Vol. 30, No. 10, (October 1987), pp. 2161-2170, ISSN 0017-9310

Benson, D.J. (2002). Volume of fluid interface reconstruction methods for multi-material problems. Applied Mechanics Reviews, Vol. 55, No. 2, (March 2002), pp. 151-165, ISSN 0003-6900

Bhat, M. S.; Poirier, D.R. \& Heinrich, J.C. (1995). Permeability for cross flow through columnar-dendritic alloys. Metallurgical and Materials Transactions B, Vol. 26, No.5, (October 1995), pp. 1049-1092, ISSN 1073-5615

Boettinger, W.J.; Coriell, S. R.; Greer, A. L.; Karma, A.; Kurz, W.; Rappaz, M. \& Trivedi, R. (2000). Solidification microstructures: recent developments, future directions, Acta Materialia, Vol. 48, No.1, (January 2000), pp. 43-70, ISSN 1359-6454

Boettinger, W. J.; Warren, J. A.; Beckermann, C. \& Karma, A. (2002). Phase-Field Simulation of Solidification, Annual Review of Materials Research, Vol. 32, pp. 163-194, ISSN 1531-7331

Boyer, R; Welsch, G. \& Collings, E.W. (1994). Materials properties handbook: titanium alloys, ASM International, ISBN 978-0871704818, Materials Park, OH

Brackbill, J.U.; Kothe, D.B. \& Zemach, C. (1992). A continuum method for modeling surface tension, Journal of Computational Physics, Vol. 100, No.2, (June 1992), pp. 335-354, ISSN 0021-9991

Caboussat, A. (2005). Numerical Simulation of Two-Phase Free Surface Flows. Archives of Computational Methods in Engineering, Vol. 12, No.2, (June 2005), pp. 165-224, ISSN 1134-3060

Carman, P.C. (1937). Fluid flow through granular beds. Transactions of the Institution of Chemical Engineers, Vol. 15, (February 1937), pp. 150-166, ISSN 0046-9858 
Caginalp, G. (1989). Stefan and Hele-Shaw type models as asymptotic limits of the phasefield equations. Physical Review A, Vol.39, No.11, (June 1989), pp. 5887-5896, ISSN 1050-2947

Choi, M.; Greif, R. \& Salcudean, M. (1987). A study of the heat transfer during arc welding with applications to pure metals or alloys and low or high boiling temperature materials, Numerical Heat Transfer, Vol. 11, No.4, (April 1987) pp. 477-491, ISSN 0149-5720

Chorin, A.J. (1968). Numerical solution of the Navier-Stokes equations. Mathematics of Computation, Vol. 22, No. 104, (October 1968), pp. 745-762, ISSN 0025-5718

Chorin, A.J. (1980). Flame advection and propagation algorithms, Journal of Computational Physics, Vol. 35, No. 1, (March 1980), pp. 1 - 11, ISSN 0021-9991

Clyne, T. W. \& Kurz, W. (1981). Solute redisribution during solidification with rapid solid state diffusion. Metallurgical Transactions A, Vol.12, No.6, (June 1981), pp. 965-971, ISSN 1073-5623

Cummins, S. J.; Francois, M. M. \& Kothe, D.B. (2005). Estimating curvature from volume fractions. Computers E Structures, Vol.83, No. 6-7, (February 2005), pp. $425-434$, ISSN 0045-7949

Debar, R. (1974). Fundamentals of the KRAKEN Code, Technical Report UCIR-760, Lawrence Livermore National Laboratory, 1974

Drummond, J. E. \& Tahir, M.I. (1984). Laminar viscous flow through regular arrays of parallel solid cylinders. International Journal of Multiphase Flow, Vol. 10, No. 5, (October 1984), pp. 515-540, ISSN 0301-9322

Eylon, D. \& Froes, F.H. (1984). Titanium Net-Shape Technologies. Journal of Metals, Vol. 36, No. 6, (June 1984), pp. 36-41, ISSN 1047-4838

Fan,Z.; Sparks, T.E.; Liou, F.; Jambunathan, A.; Bao, Y.; Ruan, J. \& Newkirk, J.W. (2007). Numerical Simulation of the Evolution of Solidification Microstructure in Laser Deposition. Proceedings of the 18th Annual Solid Freeform Fabrication Symposium, Austin, TX, USA, August 2007

Fan,Z.; Stroble,J.K.; Ruan, J.; Sparks, T.E. \& Liou, F. (2007). Numerical and Analytical Modeling of Laser Deposition with Preheating. Proceedings of ASME 2007 International Manufacturing Science and Engineering Conference, ISBN 0-7918-4290-8, Atlanta, Georgia, USA, October, 2007, pp. 37-51

Fan,Z. (2007). Numerical and Experimental Study of Parameter Sensitivity and Dilution in Laser Deposition, Master Thesis, University of Missouri-Rolla, 2007

Fan,Z.; Jambunathan, A.; Sparks, T.E.; Ruan, J.; Yang, Y.; Bao, Y. \& Liou, F. (2006). Numerical simulation and prediction of dilution during laser deposition. Proceedings of the 17th Annual Solid Freeform Fabrication Symposium, Austin, TX, USA, August 2006, pp. 532-545

Ferziger, J.H. \& Peric, M. (2002). Computational Methods for Fluid Dynamics (3rd edition), Springer-Verlag, ISBN 3-540-42074-6, Berlin Heidelberg New York

Francois, M.M.; Cummins, S.J.; Dendy, E.D.; Kothe, D.B.; Sicilian, J.M. \& Williams, M.W. (2006). A balanced-force algorithm for continuous and sharp interfacial surface tension models within a volume tracking framework. Journal of Computational Physics, Vol. 213, No. 1, (March 2006), pp. 141 - 173, ISSN 0021-9991 
Frenk, A.; Vandyoussefi, M.; Wagniere, J.; Zryd, A. \& Kurz, W. (1997). Analysis of the lasercladding process for stellite on steel. Metallurgical and Materials Transactions B, Vol. 28, No.3, (June 1997), pp. 501-508, ISSN 1073-5615

Fuster, D.; Agbaglah, G.; Josserand, C.; Popinet, S. \& Zaleski, S. (2009). Numerical simulation of droplets, bubbles and waves: state of the art. Fluid Dynamics Research, Vol.41, No.6, (December 2009), p. 065001 (24 pp.), ISSN 0169-5983

Gandin, Ch.-A. \& Rappaz, M. (1994). A coupled finite element-cellular automaton model for the prediction of dendritic grain structures in solidification processes, Acta Metallurgica et Materialia, Vol. 42, No. 7, (July 1994), pp. 2233-2246, ISSN 0956-7151

Ganesan, S. \& Poirier, D. R. (1990). Conservation of mass and momentum for the flow of interdendritic liquid during solidification, Metallurgical Transactions B, Vol. 21, No.1, (February 1990), pp. 173-181, ISSN 1073-5615

Ganesan, S.; Chan, C.L. \& Poirier, D.R. (1992). Permeability for flow parallel to primary dendrite arms. Materials Science and Engineering: A, Vol. 151, No. 2, (May 1992), pp. 97-105, ISSN 0921-5093

Gerlach, D.; Tomar, G.; Biswas, G. \& Durst, F. (2006). Comparison of volume-of-fluid methods for surface tension-dominant two-phase flows. International Journal of Heat and Mass Transfer, Vol. 49, No. 3-4, (February 2006), pp. 740-754, ISSN 0017-9310

Gibou,F.; Fedkiw, R.; Caflisch, R. \& Osher, S. (2003). A Level Set Approach for the Numerical Simulation of Dendritic Growth. Journal of Scientific Computing, Vol. 19, No.1-3, (December 2003), pp. 183-199, ISSN 0885-7474

Grujicic, M.; Cao, G. \& Figliola, R.S. (2001). Computer simulations of the evolution of solidification microstructure in the LENSTM rapid fabrication process, Applied Surface Science, Vol. 183, No. 1-2, (November 2001), pp. 43-57, ISSN 0169-4332

Gueyffier, D.; Li, J.; Nadim, A.; Scardovelli, R. \& Zaleski, S. (1999). Volume of Fluid interface tracking with smoothed surface stress methods for three-dimensional flows. Journal of Computational Physics, Vol. 152, No.2, (July 1999), pp. 423-456, ISSN 0021-9991

Hansbo, P. (2000). A Free-Lagrange Finite Element Method using Space-Time Elements. Computer Methods in Applied Mechanics and Engineering, Vol. 188, No. 1-3, (July 2000), pp. 347-361, ISSN 0045-7825

Hills, R.N.; Loper, D.E. \& Roberts, P.H. (1983). A thermodynamically consistent model of a mushy zone. The Quarterly Journal of Mechanics \& Applied Mathematics, Vol. 36, No. 4, (November 1983), pp. 505-536, ISSN 0033-5614

Hirt, C.W. \& Nichols, B.D. (1981). Volume-of-fluid (VOF) for the dynamics of free boundaries. Journal of Computational Physics, Vol. 39, No.1, (January 1981), pp. 201225, ISSN 0021-9991

Hirt, C. W. \& Nichols, B. D. (1988). Flow-3D user manual, Technical Report, Flow Sciences, Inc.

Idelsohn, S. R.; Storti, M. A. \& Onate, E. (2001). Lagrangian Formulations to Solve Free

Surface Incompressible Inviscid Fluid Flows. Computer Methods in Applied Mechanics and Engineering, Vol. 191, No. 6-7, (December 2001), pp. 583-593, ISSN 0045-7825

Jacqmin, D. (1999). Calculation of two-phase Navier-Stokes flows using phase-field modeling. Journal of Computational Physics, Vol. 155, No.1, (October 1999), pp. 96127, ISSN 0021-9991 
Jaluria, Y. (2006). Numerical Modeling of Manufacturing Processes. In: Handbook of Numerical Heat Transfer (2 edition), Minkowycz, W.J.; Sparrow, E.M. \& Murthy, J.Y., (Ed.), pp. 729-783, Wiley, ISBN 0471348783, Hoboken, New Jersey

Jones, W.P. \& Launder, B.E. (1973). The calculation of low-Reynolds-number phenomena with a two-equation model of turbulence. International Journal of Heat and Mass Transfer, Vol. 16, No. 6, (June 1973), pp.1119-1130, ISSN 0017-9310

Juric D. \& Tryggvason G. (1996). A Front-Tracking Method for Dendritic Solidification, Journal of Computational Physics, Vol. 123, No.1, (January 1996) pp. 127-148, ISSN 0021-9991

Karma, A. \& Rappel, W.J. (1996). Phase-field method for computationally efficient modeling of solidification with arbitrary interface kinetics, Physical Review E, Vol. 53, No.4, (April 1996), pp. R3017-R3020, ISSN 1063-651X

Karma, A. \& Rappel, W.J. (1998). Quantitative phase-field modeling of dendritic growth in two and three dimensions. Physical Review E, Vol. 57, No.4, (April 1998), pp. 43234329, ISSN 1063-651X

Kim, Y.T.; Goldenfeld, N. \& Dantzig, J. (2000). Computation of dendritic microstructures using a level set method. Physical Review E, Vol. 62, No.2, (August 2000). pp. 24712474, ISSN 1063-651X

Knoll, D. A.; Kothe, D. B. \& Lally, B. (1999). A new nonlinear solution method for phase change problems. Numerical Heat Transfer, Part B Fundamentals, Vol. 35, No. 4, (December 1999), pp. 436-459, ISSN 1040-7790

Kobayashi, R. (1993). Modeling and numerical simulations of dendritic crystal growth. Physica D: Nonlinear Phenomena, Vol. 63, No. 3-4, (March 1993), pp. 410-423, ISSN 0167-2789

Kobryn, P.A.; Ontko, N.R.; Perkins, L.P. \& Tiley, J.S. (2006) Additive Manufacturing of Aerospace Alloys for Aircraft Structures. In: Cost Effective Manufacture via Net-Shape Processing, Meeting Proceedings RTO-MP-AVT-139, Neuilly-sur-Seine, France: RTO, pp. 3-1 - 3-14

Kothe, D. B.; Mjolsness, R. C. \& Torrey, M. D. (1991). RIPPLE: A Computer Program for Incompressible Flows with Free surfaces, Technical Report, LA-12007-MS, Los Alamos National Lab

Lafaurie, B.; Nardone, C.; Scardovelli, R.; Zaleski, S. \& Zanetti, G. (1994). Modelling Merging and Fragmentation in Multiphase Flows with SURFER. Journal of Computational Physics, Vol. 113, No.1, (July 1994), pp. 134-147, ISSN 0021-9991

Liou, F. \& Kinsella, M. (2009). A Rapid Manufacturing Process for High Performance Precision Metal Parts. Proceedings of RAPID 2009 Conference E Exposition, Society of Manufacturing Engineers, Schaumburg, IL, USA, May 2009

Liovic, P.; Francois, M.; Rudman, M. \& Manasseh, R. (2010). Efficient simulation of surface tension-dominated flows through enhanced interface geometry interrogation. Journal of Computational Physics, Vol. 229, No. 19, (September 2010), pp. 7520-7544, ISSN 0021-9991

Lips,T. \& Fritsche, B. (2005). A comparison of commonly used re-entry analysis tools, Acta Astronautica, Vol. 57, No.2-8, (July-October 2005), pp. 312-323, ISSN 0094-5765

López, J. \& Hernández, J. (2010). On reducing interface curvature computation errors in the height function technique. Journal of Computational Physics, Vol.229, No.13, (July 2010), pp. 4855-4868, ISSN 0021-9991 
Meier, M; Yadigaroglu,G. \& Smith, B.L. (2002). A novel technique for including surface tension in PLIC-VOF methods. European Journal of Mechanics - B/Fluids, Vol. 21, No. 1, ISSN 0997-7546, pp. 61-73, ISSN 0997-7546

Mills, K. C. (2002). Recommended Values of Thermophysical Properties for Selected Commercial Alloys, Woodhead Publishing Ltd, ISBN 978-1855735699, Cambridge

Muller, I.A. (1968). A Thermodynamic theory of mixtures of fluids, Archive for Rational Mechanics and Analysis, Vol. 28, No. 1, (January 1968), pp. 1-39, ISSN 0003-9527

$\mathrm{Ni}$, J. \& Beckermann, C. (1991). A volume-averaged two-phase model for transport phenomena during solidification, Metallurgical Transactions B, Vol. 22, No.3, (June 1991), pp. 349-361, ISSN 1073-5615

Ni, J. \& Incropera, F. P. (1995). Extension of the Continuum Model for Transport Phenomena Occurring during Metal Alloy Solidification, Part I: The Conservation Equations. International Journal of Heat and Mass Transfer, Vol. 38, No. 7, (May 1995), pp. 12711284, ISSN 0017-9310

Nichols, B. D.; Hirt, C. W. \& Hotchkiss, R. S. (1980). SOLA-VOF: A solution algorithm for transient fluid flow with multiple free boundaries, Technical Report, LA-8355, Los Alamos National Lab

Noh, W.F. \& Woodward, P.R. (1976). SLIC (simple line interface calculation), Lecture Notes in Physics, Vol. 59, pp. 330 - 340, ISSN 0075-8450

Pavlyk, V. \& Dilthey, U. ( 2004). Numerical Simulation of Solidification Structures During Fusion Welding. In: Continuum Scale Simulation of Engineering Materials: Fundamentals - Microstructures - Process Applications, Raabe, D.; Franz Roters, F.; Barlat, F. \& Chen, L.Q., (Ed.), pp. 745-762, Wiley, ISBN 978-3-527-30760-9, Weinheim, Germany

Pilliod Jr., J.E. \& Puckett, E.G. (2004). Second-order accurate volume-of-fluid algorithms for tracking material interfaces. Journal of Computational Physics, Vol. 199, No. 2, (September 2004), pp. 465 - 502, ISSN 0021-9991

Poirier, D.R. (1987). Permeability for flow of interdendritic liquid in columnar-dendritic alloys. Metallurgical Transactions B, Vol. 18, No. 1, (March 1987), pp. 245-255, ISSN 1073-5615

Prantil, V. C. \& Dawson, P. R. (1983). Application of a mixture theory to continuous casting. In: Transport Phenomena in Materials Processing, Chen, M. M.; Mazumder, J. \& Tucker III, C. L., (Ed.), pp. 469-484, ASME, ISBN 978-9994588787, New York, N.Y.

Prescott, P.J.; Incropera, F.P. \& Bennon, W.D. (1991). Modeling of Dendritic Solidification Systems: Reassessment of the Continuum Momentum Equation. International Journal of Heat and Mass Transfer, Vol. 34, No. 9, (September 1991), pp. 2351-2360, ISSN 0017-9310

Provatas, N.; Goldenfeld, N. \& Dantzig, J. (1998). Efficient Computation of Dendritic Microstructures using Adaptive Mesh Refinement. Physical Review Letters, Vol. 80, No. 15, (April 1998), pp. 3308-3311, ISSN 0031-9007

Ramaswany, B. \& Kahawara, M. (1987). Lagrangian finite element analysis applied to viscous free surface fluid flow. International Journal for Numerical Methods in Fluids, Vol. 7, No. 9, (September 1987), pp. 953-984, ISSN 0271-2091

Rappaz, M. \& Gandin, Ch.-A. (1993). Probabilistic modelling of microstructure formation in solidification processes. Acta Metallurgica Et Materialia, vol.41, No. 2, (February 1993), pp. 345-360, ISSN 0956-7151 
Renardy Y. \& Renardy, M. (2002). PROST: A parabolic reconstruction of surface tension for the volume-of-fluid method. Journal of Computational Physics, Vol. 183, No. 2, (December 2002), pp. 400 - 421, ISSN 0021-9991

Rider, W.J. \& Kothe, D.B. (1998). Reconstructing volume tracking. Journal of Computational Physics, Vol. 141, No. 2, (April 1998), pp. 112-152, ISSN 0021-9991

Rudman, M. (1997). Volume-tracking methods for interfacial flow calculations. International Journal for Numerical Methods in Fluids, Vol. 24, No.7, (April 1997), pp.671-691, ISSN 0271-2091

Scardovelli, R. \& Zaleski, S. (1999). Direct numerical simulation of free-surface and interfacial flow, Annual Review of Fluid Mechanics, Vol. 31, (January 1999), pp. 567603, ISSN 0066-4189

Scardovelli R. \& Zaleski S. (2000). Analytical relations connecting linear interfaces and volume fractions in rectangular grids, Journal of Computational Physics, Vol. 164, No. 1, (October 2000), pp. 228-237, ISSN 0021-9991

Scardovelli, R. \& Zaleski, S. (2003). Interface Reconstruction with Least-Square Fit and Split Eulerian-Lagrangian Advection. International Journal for Numerical Methods in Fluids, Vol. 41, No.3, (January 2003), pp. 251-274, ISSN 0271-2091

Scheil, E. (1942). Z. Metallkd, Vol.34, pp. 70-72, ISSN 0044-3093

Sethian, J. A. (1996). Level Set Methods: Evolving Interfaces in Computational Geometry, Fluid Mechanics, Computer Vision, and Materials Science, Cambridge University Press, ISBN 978-0521572026, Cambridge, UK.

Sethian, J. A. (1999). Level Set Methods and Fast Marching Methods: Evolving Interfaces in Computational Geometry, Fluid Mechanics, Computer Vision, and Materials Science (2 edition), Cambridge University Press, ISBN 978-0521645577, Cambridge, UK.

Shirani, E.; Ashgriz, N. \& Mostaghimi, J. (2005). Interface pressure calculation based on conservation of momentum for front capturing methods. Journal of Computational Physics, Vol. 203, No. 1, (February 2005), pp. 154-175, ISSN 0021-9991

Stefanescu, D.M. (2002). Science and Engineering of Casting Solidification, Springer, ISBN 030646750X, New York, NY

Steinbach, I.; Pezzolla, F.; Nestler, B.; Seeszelberg, M.; Prieler, R.; Schmitz G.J. \& Rezende J.L.L. (1996). A phase field concept for multiphase systems. Physica D, Vol. 94, No.3, (August 1996), pp. 135-147, ISSN 0167-2789

Sullivan Jr., J. M.; Lynch, D.R. \& O'Neill, K. (1987) Finite element simulation of planar instabilities during solidification of an undercooled melt. Journal of Computational Physics, Vol. 69, No. 1, (March 1987), pp. 81-111, ISSN 0021-9991

Swaminathan, C. R. \& Voller, V. R. (1992). A general enthalpy method for modeling solidification processes. Metallurgical Transactions B, Vol. 23, No. 5, (October 1992), pp. 651-664, ISSN 1073-5615

Takizawa, A.; Koshizuka, S. \& Kondo S. (1992). Generalization of physical component boundary fitted co-ordinate method for the analysis of free surface flow. International Journal for Numerical Methods in Fluids, Vol. 15, No. 10, (November 1992), pp. 1213-1237, ISSN 0271-2091

Tang, H.; Wrobel, L.C. \& Fan, Z. (2004). Tracking of immiscible interfaces in multiplematerial mixing processes, Computational Materials Science, Vol. 29, No.1, (January 2004), pp.103 - 118, ISSN 0927-0256 
Torrey, M. D.; Cloutman, L. D.; Mjolsness, R. C. \& Hirt, C. W. (1985). NASA-VOF2D: a computer program for incompressible flow with free surfaces, Technical Report, LA101612-MS, Los Alamos National Lab

Torrey, M. D.; Mjolsness, R. C. \& Stein L. R. (1987). NASA-VOF3D: a three-dimensional computer program for incompressible flow with free surfaces, Technical Report, LA11009-MS, Los Alamos National Lab

Tryggvason, G.; Bunner, B.; Esmaeeli, A.; Juric, D.; Al-Rawahi, N.; Tauber, W.; Han, J.; Nas, S. \& Jan, Y.-J. (2001). A Front-Tracking Method for the Computations of Multiphase Flow. Journal of Computational Physics, Vol. 169, No. 2, (May 2001), pp. 708-759, ISSN 0021-9991

Udaykumar, H. S.; Mittal, R. \& Shyy, W. (1999). Computation of Solid-Liquid Phase Fronts in the Sharp Interface Limit on Fixed Grids. Journal of Computational Physics, Vol. 153, No.2, (August 1999), pp. 535-574, ISSN 0021-9991

Udaykumar, H.S.; Marella, S. \& Krishnan, S. (2003). Sharp-interface simulation of dendritic growth with convection: benchmarks. International Journal of Heat and Mass Transfer, Vol. 46, No.14, (July 2003), pp. 2615-2627, ISSN 0017-9310

Voller, V.R. \& Prakash, C. (1987). A Fixed Grid Numerical Modeling Methodology for Convection-Diffusion Mushy Region Phase Change Problems. International Journal of Heat and Mass Transfer, Vol. 30, No. 8, (August 1987), pp. 1709-1719, ISSN 00179310

Voller, V.R.; Brent, A. \& Prakash, C. (1989). The Modeling of Heat, Mass and Solute Transport in Solidification Systems, International Journal of Heat and Mass Transfer, Vol. 32, No. 9, (September 1989), pp. 1719-1731, ISSN 0017-9310

Voller, V.R.; Mouchmov, A. \& Cross, M. (2004). An explicit scheme for coupling temperature and concentration fields in solidification models. Applied Mathematical Modelling, Vol. 28, No. 1, (January 2004), pp. 79 - 94, ISSN 0307-904X

Voller, V.R. (2006). Numerical Methods for Phase-Change Problems. In: Handbook of Numerical Heat Transfer (2 edition), Minkowycz, W.J.; Sparrow, E.M. \& Murthy, J.Y., (Ed.), pp. 593-622, Wiley, ISBN 978-0-471-34878-8, Hoboken, New Jersey

Warren, J.A. \& Boettinger, W.J. (1995) Prediction of dendritic growth and microsegregation patterns in a binary alloy using the phase-field method. Acta Metallurgica et Materialia,

Vol. 43, No. 2, (February 1995), pp. 689-703, ISSN 0956-7151

West, R. (1985). On the permeability of the two-phase zone during solidification of alloys. Metallurgical and Materials Transactions A, Vol. 16, No. 4, (April 1985), pp. 693, ISSN 1073-5623

Wheeler, A.A.; Boettinger, W.J. \& McFadden, G.B. (1992). Phase-field model for isothermal phase transitions in binary alloys. Physical Review A, Vol. 45, No. 10, (May 1992), pp. $7424-7439$, ISSN 1050-2947

Youngs, D.L. (1982). Time-dependent multi-material flow with large fluid distortion. In: Numerical Methods for Fluid Dynamics, Morton, K.W. \& Baines, M. J. (Ed.), pp. 273-285, Academic Press, ISBN 9780125083607, UK

Youngs, D.L. (1984). An Interface Tracking Method for a 3D Eulerian Hydrodynamics Code, Technical Report 44/92/35, AWRE, 1984 
Yu, K.O. \& Imam, M.A. (2007). Development of Titanium Processing Technology in the USA. Proceedings of the 11th World Conference on Titanium (Ti-2007), Kyoto, Japan, June 2007

Zhu, M. F.; Lee, S. Y. \& Hong, C. P. (2004). Modified cellular automaton model for the prediction of dendritic growth with melt convection. Physical Review E, Vol. 69, No.6, (June 2004), pp. 061610-1 - 061610-12, ISSN 1063-651X 


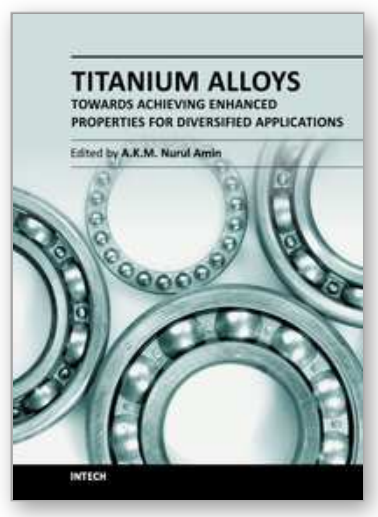

\author{
Titanium Alloys - Towards Achieving Enhanced Properties for \\ Diversified Applications
}

Edited by Dr. A.K.M. Nurul Amin

ISBN 978-953-51-0354-7

Hard cover, 228 pages

Publisher InTech

Published online 16, March, 2012

Published in print edition March, 2012

The first section of the book includes the following topics: fusion-based additive manufacturing (AM) processes of titanium alloys and their numerical modelling, mechanism of ?-case formation mechanism during investment casting of titanium, genesis of gas-containing defects in cast titanium products. Second section includes topics on behavior of the (? + ?) titanium alloys under extreme pressure and temperature conditions, hot and super plasticity of titanium (? + ?) alloys and some machinability aspects of titanium alloys in drilling. Finally, the third section includes topics on different surface treatment methods including nanotube-anodic layer formation on two phase titanium alloys in phosphoric acid for biomedical applications, chemico-thermal treatment of titanium alloys applying nitriding process for improving corrosion resistance of titanium alloys.

\title{
How to reference
}

In order to correctly reference this scholarly work, feel free to copy and paste the following:

Zhiqiang Fan and Frank Liou (2012). Numerical Modeling of the Additive Manufacturing (AM) Processes of Titanium Alloy, Titanium Alloys - Towards Achieving Enhanced Properties for Diversified Applications, Dr. A.K.M. Nurul Amin (Ed.), ISBN: 978-953-51-0354-7, InTech, Available from:

http://www.intechopen.com/books/titanium-alloys-towards-achieving-enhanced-properties-for-diversifiedapplications/numerical-modeling-of-the-additive-manufacturing-am-processes-of-titanium-alloys

\section{INTECH}

open science | open minds

\author{
InTech Europe \\ University Campus STeP Ri \\ Slavka Krautzeka 83/A \\ 51000 Rijeka, Croatia \\ Phone: +385 (51) 770447 \\ Fax: +385 (51) 686166 \\ www.intechopen.com
}

\author{
InTech China \\ Unit 405, Office Block, Hotel Equatorial Shanghai \\ No.65, Yan An Road (West), Shanghai, 200040, China \\ 中国上海市延安西路65号上海国际贵都大饭店办公楼405单元 \\ Phone: +86-21-62489820 \\ Fax: $+86-21-62489821$
}


(C) 2012 The Author(s). Licensee IntechOpen. This is an open access article distributed under the terms of the Creative Commons Attribution 3.0 License, which permits unrestricted use, distribution, and reproduction in any medium, provided the original work is properly cited. 